\title{
Effects of EMG Biofeedback on Pain and Quality of Life in Cervical Dystonia
}

\section{Jahanbazi $A^{1 *}$, Chitsaz $A^{2}$ and Asgari $K^{3}$}

${ }^{1}$ MA of Psychology, Department of Psychology, University of Isfahan, Isfahan, Iran

${ }^{2}$ Associate Professor, Department of Neurology, Isfahan University of Medical Sciences, Isfahan, Iran

${ }^{3}$ Assistant Professor, PhD of Clinical Psychology, Department of Psychology, University of Isfahan, Isfahan, Iran

\begin{abstract}
Cervical dystonia (CD) is a focal dystonia affecting cervical muscles leading to abnormal postures and movements of the head, neck and shoulders. Cervical dystonia is a chronic disease with unwanted side effects. Although muscle contractions represent the most visible disease feature, associated symptoms such as pain are frequent and relevant contributors to disability. At the same time, pain constitutesone of the most important factors in term of poor quality of life $(\mathrm{QOL})$ and is one of the most affected $\mathrm{QOL}$ domains in $\mathrm{CD}$ patients.

However, the mechanism underlying the pain associated with $C D$ remains unclear. There are no therapeutic controlled trials that have evaluated pain or QOL as a primary outcome, but the available data suggest that therapeutic interventions that improve dystonia also alleviate pain and have a beneficial effect on QOL. Recent studies have demonstrated that Electromyography (EMG) biofeedback is a good option for treatment of CD. The main aim of present research was to investigate the effect of EMG biofeedback on pain and health related quality of life of cervical dystonia patients. To do so, a sample of 30 subjects with cervical dystonia was selected for experimental and control groups by an accessible sampling procedure. Subjects were assessed with the pain subscale of Toronto Western Spasmodic Torticollis Rating Scale (TWSTRS) and the Short-form Health Survey with 36 questions (SF-36) in two stages (pre-test, post-test). The obtained data were analyzed through covariance analysis method. After 30 sessions of EMG biofeedback training, the mean scores of pain in the experimental group were significantly diminished. Also, the mean of SF-36 scores in the experimental group showed a significantly higher increase in comparison to that of the control group. The results suggested that EMG biofeedback was effective on pain and health related QOL of CD patients.
\end{abstract}

Keywords: Cervical dystonia; Pain; Quality of life; Biofeedback

\section{Introduction}

Cervical dystonia $(\mathrm{CD})$ is the most frequent form of adult-onset focal dystonia [1]. Its main clinical feature is torsion of the neck, which is the consequence of anomalous and involuntary contractions of the cervical muscles [2]. CD is often defined as "spasmodic torticollis". While this term recalls the main clinical feature of $\mathrm{CD}$, it does not provide any information about the nature of the disease [3]. Indeed, torticollis can arise not only from peripheral or central nervous system alterations, but also from bone, joint, or muscle disease [4]. Although the first descriptions of dystonia appeared early in the 1900s, more than half a century passed before physicians realized that this bizarre condition was linked to brain disease [5]. Although the pathophysiology of $\mathrm{CD}$ still remains unclear, a recent review suggests that dystonia may result from functional disturbance of the basal ganglia, possibly involving striatal control of the globuspallidus and, consequently, thalamic control of cortical motor planning and execution [6]. At least two-thirds of the $\mathrm{CD}$ patients report pain that significantly contributes to the disability associated with their disorder [7]. Although pain is most frequently localized to the back of the neck and shoulders, it may also involve the head, upper chest, upper arms, and other areas [8]. The mechanism of pain in $\mathrm{CD}$ remains mostly unknown. A small study has suggested a decreased threshold of pain perception in CD patients, which could point to the involvement of central processes in addition to local muscle involvement [9]. Other potential causes of pain in $\mathrm{CD}$ are orthopedic complications including cervical spine degeneration, spondylosis, disc herniation, vertebral subluxations and fractures, radiculopathies and myelopathies [10].

Dystonia has a negative impact on quality of life (QOL). A study on focal, segmental and generalized dystonia found that the QOL of dystonic patients was worse in all domains, but mainly in those related to physical and social functioning [11].

CD has a negative impact on QOL compared with age- and gender- matched healthy control subjects [12]. Several studies have tried to identify the most affected domains and the major determinants of QOL in patients with CD [13]. Many studies have reported a major impact of $\mathrm{CD}$ on pain and in domains of role limitation (physical and emotional), mental health and social and physical functioning, as measured by the Medical Outcomes Study Short-Form 36 (SF-36), ageneric QOL measure [14]. Currently, $\mathrm{CD}$ is an incurable disease [15]. Available symptomatic interventions should aim not only at the relief of dystonia and the associated symptoms, but also to decrease functional disability and improve QOL. Ideally, the prevention of longterm complications should also be one of the therapeutic goals [16]. Therapeutic interventions for $\mathrm{CD}$ are broadly divided into botulinum toxin (BoNT), oral drugs, surgical interventions, physical therapy and EMG biofeedback [17]. Despite the use of different treatment, dystonic patients still do not fully recover. Usually the symptoms of dystonia are transformed over time into chronic symptoms that do not go away and continues for a lifetime. Due to the side effects of drug treatments and surgery, today's researchers and clinicians are seeking effective treatment methods for patients who have fewer side effects [3].

Biofeedback is a form of behavioral medicine, which assists patients in learning enhanced sensory discrimination to facilitate the acquisition

*Corresponding author: Jahanbazi A, MA of Psychology, Faculty of Psychology and Educational Sciences, Isfahan University, Isfahan, Iran, Tel: 8174673441; E-mail: anis.jahanbazi@gmail.com

Received October 12, 2013; Accepted November 28, 2013; Published November 30,2013

Citation: Jahanbazi A, Chitsaz A, Asgari K (2013) Effects of EMG Biofeedback on Pain and Quality of Life in Cervical Dystonia. J Neurol Disord 2: 144 doi:10.4172/2329-6895.1000144

Copyright: (c) 2013 Jahanbazi A, et al. This is an open-access article distributed under the terms of the Creative Commons Attribution License, which permits unrestricted use, distribution, and reproduction in any medium, provided the original author and source are credited. 
of physiological self-regulation skills to reduce symptoms, identify and avoid aggravating activities, enhance function and speed recovery to pre-injury status [18]. Biofeedback has been used in clinical settings for treatment and rehabilitation of injured workers for more than 30 years [19]. Biofeedback is the process of identifying physiological variables such as muscle activity, peripheral skin temperature, regional blood flow, respiratory style and rate, heart rate variability, brainwaves and other measures of autonomic nervous system function for the purpose of helping the patient to develop a greater sensory awareness [20]. This is achieved by the monitoring of these variables with the use of electronic instrumentation, which is then fed back to the individual visually or audibly, for the purpose of teaching the individual to gain some measure of physiological control [21]. Surface Electromyography (SEMG) is used for self-management of pain and stress reactions involving muscle tensions and reduction of over-effort related to poor posture or undesirable movement habits [22].

\section{Method}

This is an experimental study with pre-test and post-test plan with control group. In this study, EMG biofeedback training is considered as independent variable and pain and QOL as dependent variable.

30 patients were consecutively recruited at five medical centers in Iran. The main criteria for inclusion in the study were the presence of $\mathrm{CD}$, with illness duration of at least oneyear, and freedom from any pharmacological (oral or infiltrative) CD therapy at the time of the study. None ofthe patients were on any medication at the time of the study. 10 patients had previously been treated with botulinum toxin, but with no significant improvementof their torticollis. In these patients, botulinum toxin therapy had been terminated at least six months before our study. The other patients had never received botulinum toxin therapy. None of the patients showed tremor. Neither neurophysiological (somatosensory evoked potentials, transcranial magnetic stimulation, EMG recording) nor radiological (cervical X-ray, MRI of the brainand spinal cord) investigations revealed any abnormalities of the spine, peripheral, or central nervous systemto which the dystonic symptoms might be attributed. Allthe subjects gave their informed consent before entering the study.

The range of samples age was 22-51 years old with average 34.06 and standard deviation 8.07. The obtained data were analyzed through covariance analysis method with SPSS version 17.

\section{Instruments}

\section{Biofeedback amplifier}

Biofeedback amplifier is a device which analyzes the received physiological variables such as muscle activity, muscle contraction, peripheral skin temperature, regional blood flow, respiratory style and rate, heart rate variability, brainwaves and other measures of autonomic nervous system function for the purpose of helping the patient to develop a greater sensory awareness, through located electrodes on the different parts of body [23]. This is achieved by the monitoring of these variables with the use of electronic instrumentation, which is then fed back to the individual visually or audibly, for the purpose of teaching the individual to gain some measure of physiological control. Once an initial assessment is made and individualized needs are identified, the biofeedback specialist acts as a coach to teach and guide each individual to reach targeted goals of increased function [20]. Surface Electromyography (SEMG) is used for self-management of pain and stress reactions involving muscle tension and for reduction of overeffort related to poor posture or undesirable movement habits [21].
In this study researchers used a Biofeedback device, made by "Thought Technology Ltd." that called "ProComp Infiniti" that is a 10 channel device and "BioGraphInfiniti software"(Physiology suite section) that is designed to work with a number of sensors. The sensor that was used in this study is "Myoscan-Pro EMG $(\mathrm{P} / \mathrm{N}$ : SA94O1M-60)". The MyoScan-Pro is a pre-amplified surface EMG sensor for use on low sampling rate encoder inputs and designed to measure Root Mean Square (RMS) SEMG used for stress assessment and SEMG Biofeedback. Disposable EKG/EMG electrodes used in this study include: (A) T3402M-Triode electrode, with standard $2 \mathrm{~cm}$ spacing of silver-silver chloride electrodes, backed with nickel plated brass snaps to prevent corrosion, (B) T3425 UniGel electrodes, for use with the EKG sensor or EMG, in case of sensitive placements on dry skin and (C) T3404-Single strip electrodes, versatile electrodes can be used as strip or separated for wider placements. The ProComp infinity system contains all the peripherals to easily connect it to a desktop or laptop IBM-compatible PC.

\section{Toronto western spasmodic torticollis rating scale (TWSTRS)}

The TWSTRS is a validated and widely utilized scale [24]. The Toronto Western Spasmodic Torticollis Rating Scale (TWSTRS), an investigator-applied scale, is the gold standard tool for evaluation of $\mathrm{CD}$. It is composed of three subscales designed to assess the motor aspects of $C D$, measure the impact of $C D$ on activities of daily living, and quantify pain caused by $\mathrm{CD}$ and its conse $\neg$ quences on life of affected individuals. The TWSTRS is a composite scale which covers different features of CD [25]. The first part is based on the physical findings (severity subscale), the second part rates disability, and the third part pain. The TWSTRS is a validated scale which has been frequently applied in clinical trials as the primary outcome parameter. The rates of agreement for all individual components of the TWSTRS and the total TWSTRS were statistically significant (all $p<0.01)$. The interrater agreement was highest for rotation, anterocollis, and retrocollis and lowest for lateral shift. The validity ofthe questionnairehas been reportedinprevious studiesbetween $0 / 78$ and $0 / 91$ [26]. In this study researchers use the pain subscale of TWSTRS.

\section{Short-form health survey (SF-36)}

The SF-36 is a generic instrument that provides a profile assessment of HR-QOL in 8 domains: physical functioning $(\mathrm{PF})$, role functioning physical (RP), bodily pain (BP), general health $(\mathrm{GH})$, vitality (VT), social functioning $(\mathrm{SF})$, role functioning emotional (RE), and mental health $(\mathrm{MH})$. Scoring and the calculation of scales were performed by using the original Ware's method. Quality of life scales were presented as $T$ scores (mean 50; S.D. $=10)$, which were obtained by linear transformation of raw scores that facilitates comparisons across the multiple scales of the SF-36. The items can be summed to give scores out of 100, ranging from 0 (worst possible health state) to 100 (best possible health state), i.e., higher values indicate better functioning and well-being [27]. The validity of the questionnaire has been reported in previous studies between $0 / 77$ and $0 / 90$ [28].

\section{Procedure}

For each subject 30 EMG Biofeedback training sessions was held and each session lasted 45 minutes. The experimental group received feedback based on their performance, in contrast control group's feedback was not based on their performance (in fact their sessions weren't biofeedback training and they didn't know that they conducted placebo training). In the first session, before biofeedback training, a TWSRTS test and SF-36 questioner were performed on all subjects, individually. Then biofeedback training was carried out for 
Citation: Jahanbazi A, Chitsaz A, Asgari K (2013) Effects of EMG Biofeedback on Pain and Quality of Life in Cervical Dystonia. J Neurol Disord 2: 144. doi:10.4172/2329-6895.1000144

Page 3 of 6

experimental group according to the biofeedback medical treatment guidelines that compiled and edited by the biofeedback society of California [23]. During SEMG biofeedback training electrodes are located on muscle around the neck such as Trapezius, Splenius Capitis and Sternocleidomastoid according to neurologist diagnosis. Treatment goals are:

1. Improve the patient's awareness to assist in the control of muscle activity. A variety of muscle (EMG) placements from the involved quarter may be employed that relate to the symptoms. Muscle discrimination practice (alternative recruitment of agonist, quieting of antagonist and then the reverse) is important to improve sensory awareness and muscle control.

2. Reinforce the release of muscle tension that is being obtained from slow stretches, muscle control exercises, and abdominal breathing for general relaxation and lowering of arousal.

3. Improve the patient's ability to feel like they can affect their physical responses and symptoms through the feedback process. Postural issues and hand warming can be addressed as indicated to alter movement patterns and further improve self-regulation.

4. Assist in reducing dystonic motions by modifying any aspects of posture andmovement technique that can be altered.

\section{Data Analysis}

Data were analyzed using SPSS (Statistical Packages for the Social
Sciences) PC version 17 for Windows. All differences were considered significant if the probability of error was $p<0.05$. The obtained data were analyzed through covariance analysis method.

\section{Results}

To evaluate mean and standard deviation of subjects' pain scores in pre and post-test descriptive analysis was used. The results have been demonstrated in Table 1.

As has been shown in Table 1, the experimental subjects' mean of severity of pain scores in pre and post-test were 6.51 and 2.8 , the mean of duration of pain scores in pre and post-test were 4.2 and 1.4, and the mean of disability due to pain scores in pre and post-test were 4.1 and 1.06, respectively. In addition, the results showed that the control subjects' mean of severity of pain in pre and post-test were 5.7 and 5.6, the mean of duration of pain scores in pre and post test were 4.2 and 4.2 , and the mean of disability due to pain scores in pre and post-test were 3.4 and 3.6 , respectively.

In the present study in order to compare differences between cervical dystonia patients and control groups on pain scores, the individual's scores on pain subscale of TWSRTS questionnaire in post-test stage were evaluated as multivariate analysis of variance (MANOVA). The MANOVA's results have been given in Table 2.

As have been shown in Table 2, MANOVA revealed significant differences between experimental and control groups on severity of pain scores $\mathrm{F}=98.95, \mathrm{P}<0.000$. In addition, the results showed that duration of pain score $\mathrm{F}=73.46, \mathrm{P}<0.000$ and disability due to pain score $\mathrm{F}=54.16, \mathrm{P}<0.000$, were significantly different between two

\begin{tabular}{|c|c|c|c|c|c|c|c|c|}
\hline \multirow{3}{*}{$\begin{array}{l}\text { TWSRTS } \\
\text { Variable }\end{array}$} & \multicolumn{4}{|l|}{ Control group } & \multicolumn{4}{|l|}{ Experimental group } \\
\hline & \multicolumn{2}{|l|}{ Pre-test } & \multicolumn{2}{|l|}{ Post-test } & \multicolumn{2}{|l|}{ Pre-test } & \multicolumn{2}{|l|}{ Post-test } \\
\hline & Standard deviation & mean & Standard deviation & mean & Standard deviation & mean & Standard deviation & mean \\
\hline Severity of pain & 1.41 & 5.7 & 1.49 & 5.6 & 1.39 & 6.51 & 1.08 & 2.8 \\
\hline Duration of pain & 0.86 & 4.2 & 0.7 & 4.2 & 0.94 & 4.2 & 1.12 & 1.4 \\
\hline Disability due to pain & 1.24 & 3.4 & 1.18 & 3.6 & 0.83 & 4.1 & 1.09 & 1.06 \\
\hline
\end{tabular}

Table 1: Mean and standard deviation of pain scores in pre- and post-test.

\begin{tabular}{|c|c|c|c|c|}
\hline TWSRTS & & Df & $\mathbf{F}$ & $\mathbf{P}$ \\
\hline \multirow{3}{*}{ Model } & Severity of pain & 4 & 49.35 & 0.000 \\
\hline & Duration of pain & 4 & 55.76 & 0.000 \\
\hline & Disability due to pain & 4 & 30.21 & 0.000 \\
\hline \multirow{3}{*}{ Group } & Severity of pain & 1 & 98.95 & 0.000 \\
\hline & Duration of pain & 1 & 73.46 & 0.000 \\
\hline & Disability due to pain & 1 & 54.16 & 0.000 \\
\hline \multirow{3}{*}{ Error } & Severity of pain & 25 & & \\
\hline & Duration of pain & 25 & & \\
\hline & Disability due to & 25 & & \\
\hline
\end{tabular}

Table 2: MANOVA's results of TWSRTS.

\begin{tabular}{|c|c|c|c|c|c|c|c|c|}
\hline \multirow{3}{*}{$\begin{array}{c}\text { SF-36 } \\
\text { Variable }\end{array}$} & \multicolumn{4}{|l|}{ Control group } & \multicolumn{4}{|l|}{ Experimental group } \\
\hline & \multicolumn{2}{|l|}{ Pre test } & \multicolumn{2}{|l|}{ Post test } & \multicolumn{2}{|l|}{ Pre test } & \multicolumn{2}{|l|}{ Post test } \\
\hline & Standard deviation & Mean & Standard deviation & Mean & Standard deviation & mean & Standard deviation & Mean \\
\hline Physical function & 6.77 & 52.33 & 13.94 & 49.66 & 16.37 & 53.66 & 7.61 & 72.5 \\
\hline Social function & 11.76 & 35 & 12.2 & 36.50 & 7.81 & 29.96 & 9.98 & 49.16 \\
\hline Role-physical & 18.58 & 53.33 & 19.97 & 48.33 & 16.36 & 50 & 6.45 & 73.33 \\
\hline Role-emotional & 16.1 & 22 & 16.1 & 22 & 20.52 & 22.06 & 20.83 & 55.6 \\
\hline Mental health & 8.83 & 28.51 & 9.07 & 28.22 & 12.26 & 26.44 & 10.35 & 47.92 \\
\hline Vitality & 7.74 & 19.46 & 7.83 & 19 & 7.48 & 18.33 & 12.14 & 33.40 \\
\hline Body pain & 12.53 & 50.13 & 13.35 & 49.66 & 16.37 & 41.23 & 8.54 & 66.33 \\
\hline General health & 6.77 & 27.66 & 6.93 & 26.33 & 7.76 & 25.66 & 8.16 & 36.66 \\
\hline
\end{tabular}

Table 3: Mean and standard deviation of QOL scores in pre- and post-test. 
groups. Significant differences between groups reflected that dystonic subject had fewer score on pain scale than control participates after EMG biofeedback training.

To evaluate mean and standard deviation of subjects' QOL scores in pre and post-test descriptive analysis was used. The results have been demonstrated in Table 3.

As has been shown in Table 3, the experimental subjects' mean of physical function scores in pre and post-test were 53.66 and 72.5, the mean of function in pre and post-test were 29.96 and 49.16, the mean of role physical limitation in pre and post-test were 50 and 73.33 , the mean of role-emotional limitation in pre and post-test were 22.06 and 55.6, the mean of mental health in pre and post-test were 26.44 and 47.92 , the mean of vitality in pre and post-test were 18.33 and 33.40 , the mean of bodily pain in pre and post-test were 41.23 and 66.33 and the mean of general health in pre and post-test were 25.66 and 36.66 , respectively. In addition, the results showed that the control subjects' mean of physical function scores in pre and post-test were 6.77 and 13.94, the mean of function in pre and post-test were 11.76 and 12.2, the mean of role physical limitation in pre and post-test were 18.58 and 19.97, the mean of role-emotional limitation in pre and post-test were 16.1 and 16.1, the mean of mental health in pre and post-test were 8.83 and 9.07 , the mean of vitality in pre and post-test were 7.74 and 7.83 , the mean of bodily pain in pre and post-test were 12.53 and 13.35 and the mean of general health in pre and post-test were 6.77 and 6.93 , respectively.

In the present study in order to compare differences between dystonic patients and control groups on QOL scores, the individual's scores on SF-36 questionnaire and its subscales in post-test stage were evaluated as multivariate analysis (MANOVA). The MANOVA's results have been given in Table 4. As have been shown in Table 4, MANOVA revealed significant differences between experimental and control groups on physical function $\mathrm{F}=32.129, \mathrm{P}<0.001$, social function

\begin{tabular}{|c|c|c|c|c|}
\hline SF-36 & & Df & $\mathbf{F}$ & $\mathbf{P}$ \\
\hline \multirow{8}{*}{ Model } & Physical function & 10 & 5.424 & 0.0001 \\
\hline & Social function & 10 & 10.508 & 0.0001 \\
\hline & Role-physical & 10 & 5.012 & 0.0001 \\
\hline & Role-emotional & 10 & 8.139 & 0.0001 \\
\hline & Mental health & 10 & 8.841 & 0.0001 \\
\hline & Vitality & 10 & 28.593 & 0.0001 \\
\hline & Bodily pain & 10 & 5.531 & 0.0001 \\
\hline & General health & 10 & 15.014 & 0.0001 \\
\hline \multirow{8}{*}{ Group } & Physical function & 1 & 32.129 & 0.0001 \\
\hline & Social function & 1 & 60.417 & 0.0001 \\
\hline & Role-physical & 1 & 24.032 & 0.0001 \\
\hline & Role-emotional & 1 & 24.032 & 0.0001 \\
\hline & Mental health & 1 & 38.332 & 0.0001 \\
\hline & Vitality & 1 & 54.5 & 0.0001 \\
\hline & Bodily pain & 1 & 25.99 & 0.0001 \\
\hline & General health & 1 & 67.59 & 0.0001 \\
\hline \multirow{9}{*}{ Error } & Physical & 19 & & \\
\hline & function & 19 & & \\
\hline & Social function & 19 & & \\
\hline & Role-physical & 19 & & \\
\hline & Role-emotional & 19 & & \\
\hline & Mental health & 19 & & \\
\hline & Vitality & 19 & & \\
\hline & Bodily pain & 19 & & \\
\hline & General health & 19 & & \\
\hline
\end{tabular}

Table 4: MANOVA's results for SF-36.
$\mathrm{F}=60.417, \mathrm{P}<0.001$, role physical limitation $\mathrm{F}=24.032, \mathrm{P}<0.001$, role emotional limitation $\mathrm{F}=24.032, \mathrm{P}<0.001$, mental health $\mathrm{F}=38.332$, $\mathrm{P}<0.001$, vitality $\mathrm{F}=54.5, \mathrm{P}<0.001$, bodily pain $\mathrm{F}=25.99, \mathrm{P}<0.001$, and general health $\mathrm{F}=67.59, \mathrm{P}<0.001$. Significant differences between groups reflected that dystonic subject had greater score on QOL scale than control participates after EMG biofeedback training.

\section{Discussion}

The main aim of the present study was to investigate the effect of EMG biofeedback training on pain and quality of life of cervical dystonia patients. The results showed that EMG biofeedback training decrease pain and improved QOL of these subjects. Briefly, these studies show that EMG biofeedback techniques can produce a symptomatic improvement of $\mathrm{CD}$ that may last up to several months. $\mathrm{CD}$ is a chronic disorder that has a severe impact on the QOL of patients [29-31]. Pain is present in almost two-thirds of patients with $\mathrm{CD}$ and represents one of the QOL domains that is most affected in CD [31]. The main determinants for a poor QOL are depression, anxiety and pain [13]. Although there are no specific trials that have evaluated the effect of pharmacological, surgical or physical treatments on pain or QOL as primary outcomes, the best data available suggest that all interventions that have improved dystonia have also alleviated pain and improved QOL domains [31]. Human beings normally have voluntary control through the central nervous system over muscle activity. However, human beings have little experience in identifying and controlling many muscle groups [20]. CD patients often carry high level of tension in the neck and shoulders, yet often are not able to judge the level of tension [21]. A surface EMG biofeedback device uses sensors placed on the surface of the skin to read the electrical activity in the muscle beneath the skin. The more electrical activity, the more tense the muscle group is [32]. The biofeedback devise may use a meter to show the current level of tension, or send a signal with bar graph, a beeping sounder or a visual display on a computer screen. In each case, the person who receives immediate information about the level of tension in muscle group can learn to better assess the tension him or herself, and can also learn to relax the muscle. That process is helpful for CD patients, whose high muscle tension often worsens pain and abnormal postures [33]

It seems that the EMG biofeedback from inappropriately contracting muscle results in noactivation in these muscles. Since some of the symptoms are produced by over activation of muscles, such non-activation or reduced activation would result in an amelioration of symptoms [34]. This is precisely what was observed during selective muscle EMG biofeedback. Such reduced activation may be brought about by attentional factors [35]. During EMG biofeedback the patient becomes aware of overactivation and he/she is in a better position to manipulate muscle tension through attention [36]. This could operate at a voluntary or an involuntary level. This finding is supported by the fact that event-related potentials of cortex are susceptible to attention and voluntary influences [37]. Selective EMG biofeedback may be superior to treatment by injection of BoNT in two ways: first, it influences a relatively larger number of muscle groups and reduces their overactivity; and second, unlike a BoNT injection, it does not permanently decrease the performance of the muscle. In conclusion, biofeedback reduces overactivity of muscle groups responsible for dystonic posture, thereby alleviating symptoms [38]. Since overactivity of muscle is associated with the symptoms of $\mathrm{CD}$, the patients learn to undo it during the biofeedback session [39]. This learning later, as we have observed, is manifest without the aid of EMG biofeedback. Thus EMG-BF may work in two ways: first, by making the subject aware of abnormal contractions and, second, by controlling/reducing 
Citation: Jahanbazi A, Chitsaz A, Asgari K (2013) Effects of EMG Biofeedback on Pain and Quality of Life in Cervical Dystonia. J Neurol Disord 2: 144. doi:10.4172/2329-6895.1000144

Page 5 of 6

excessive contraction in involved muscle groups [40]. This could be brought about by voluntary decreased flow of motor activity (efferent control of motor mechanism) or by decreasing abnormal sensory input from muscle (muscle efferent block [41]. One study has speculated that muscle afferents play a pivotal role in dystonia [32]. Since most of the symptoms are due to abnormal contractions of agonists and antagonists, such relaxation of muscle groups leads to alleviation of discomfort and pain and correction of the dystonic posture. Improvement by biofeedback in no way denies the existence of organic lesions in the brain, as biofeedback may be working at a volitional motor learning level [42]. There is also a possibility of the existence of local or general excessive sympathetic activation in these patients [43]. This point is favored by the tonic nature of the contraction of muscles involved in the dystonic posture and appearance of pain. There is also the possibility of y motor neuron dysfunction (specifically, hyperfunction), which normally enhances tone and provides background support for voluntary activities [44]. This hyper-function may have its origin at the spinal or brain-stem level. Such disinhibition in the $y$ motor neuron circuitry has been proposed as a possible mechanism for myofascial pain symptoms [45]. The involvement of cortical sensory areas has been shown by elegant studies, both in terms of anatomical changes and by physiologic variables [46]. However, what neurophysiologic process operates during a biofeedback intervention needs to be studied [47].

Thus, specific muscle EMG biofeedback appears to be a promising nonpharmacologic intervention procedure to manage cervical dystonia. An attempt may be made to extend this method to other types of dystonia.

\section{References}

1. Fahn S, Bressman SB, Marsden CD (1998) Classification of dystonia. Adv Neurol 78: 1-10.

2. Tsui JK (1995) Cervicaldystonia.Handbook of dystonia. NewYork: Marcel Dekker, Inc.

3. Camargo $\mathrm{CH}$, Teive HA, Becker N, Baran MH, Scola RH, et al. (2008) Cervical dystonia: clinical and therapeutic features in 85 patients. Arq Neuropsiquiatr 66: 15-21.

4. Standaert DG (2011) Update on the pathology of dystonia. Neurobiol Dis 42: 148-151.

5. Comella C (2010) Dystonia. Mov Disord 31: 367-375.

6. Chan J, Brin MF, Fahn S (1991) Idiopathic cervical dystonia: clinical characteristics. Mov Disord 6: 119-126.

7. Jankovic J, Leder S, Warner D, Schwartz K (1991) Cervical dystonia: clinical findings and associated movement disorders. Neurology 41: 1088-1091.

8. Sheehy MP, Marsden CD (1980) Trauma and pain in spasmodic torticollis. Lancet 1: 777-778.

9. Kutvonen O, Dastidar P, Nurmikko T (1997) Pain in spasmodic torticollis. Pain 69: $279-286$

10. Lobbezoo F, Tanguay R, Thon MT, Lavigne GJ (1996) Pain perception in idiopathic cervical dystonia (spasmodic torticollis). Pain 67: 483-491.

11. Page D, Butler A, Jahanshahi M (2007) Quality of life in focal, segmental, and generalized dystonia. Mov Disord 22: 341-347.

12. Camfield L, Ben-Shlomo Y, Warner TT; Epidemiological Study of Dystonia in Europe Collaborative Group (2002) Impact of cervical dystonia on quality of life. Mov Disord 17: 838-841.

13. Ben-Shlomo Y, Camfield L, Warner T; ESDE collaborative group (2002) What are the determinants of quality of life in people with cervical dystonia? J Neurol Neurosurg Psychiatry 72: 608-614.

14. Cano SJ, Thompson AJ, Bhatia K, Fitzpatrick R, Warner TT, et al. (2007) Evidence-based guidelines for using the Short Form 36 in cervical dystonia. Mov Disord 22: 122-126.
15. Adam OR, Jankovic J (2007) Treatment of dystonia. Parkinsonism Relat Disord 13 Suppl 3: S362-368.

16. Ferreira JJ, Costa J, Coelho M, Sampaio C (2007) The management of cervical dystonia. Expert Opin Pharmacother 8: 129-140.

17. Jankovic J (2006) Treatment of dystonia. Lancet Neurol 5: 864-872.

18. Yucha C, Gilbert C (2004) Evidence-Based Practice in Biofeedback and Neurofeedback. Association for Applied Psychophysiology and Biofeedback Wheatridge, Colorado.

19. Kasman GS, JR Cram (1997) SEMG-triggered neuromuscular electrical stimulation. Clinical applications in surface electromyography. Gaithersburg, Maryland, Aspen Publishers, Inc.

20. Cleeland CS (1983) Biofeedback and other behavioural techniques in the treatment of disorders of voluntary movement. In Basmajian, J. V, ed. Biofeedback: principles and practice for clinicians. Baltimore: Williams \& Wilkins.

21. Clasby R, Derro D, Snelling R, Donaldson S (2003) The use of surface electromyographic techniques in assessing musculoskeletal disorders in production operations. Appl Psychophysiol Biofeedback 28: 161-165.

22. Kasman G, Cram R (1997) Clinical applications in surface electromyography Gaithersburg, Maryland, Aspen Publishers, Inc.

23. Bender K, Malewics C, Drysdale D, Sharp K, Yucca C (2007) Biofeedback Medical Treatment Guidelines. The Biofeedback Society of California Committee on Biofeedback Treatmen Guidlelines for Work Injuries.

24. Comella CL, Stebbins GT, Goetz CG, Chmura TA, Bressman SB, et al. (1997) Teaching tape for the motor section of the Toronto Western Spasmodic Torticollis Scale. Mov Disord 12: 570-575.

25. Albanese A, Sorbo FD, Comella C, Jinnah HA, Mink JW, et al. (2013) Dystonia rating scales: critique and recommendations. Mov Disord 28: 874-883.

26. Cloud LJ, Jinnah HA (2010) Treatment strategies for dystonia. Expert Opin Pharmacother 11: 5-15.

27. Bowling A, Bond M, Jenkinson C, Lamping DL (1999) Short Form 36 (SF36) Health Survey questionnaire: which normative data should be used? Comparisons between the norms provided by the Omnibus Survey in Britain the Health Survey for England and the Oxford Healthy Life Survey. J Public Health Med 21: 255-270.

28. Montazeri A, Goshtasebi A, Vahdaninia M, Gandek B (2005) The Short Form Health Survey (SF-36): translation and validation study of the Iranian version. Qual Life Res 14: 875-882.

29. Müller J, Kemmler G, Wissel J, Schneider A, Voller B, et al. (2002) The impact of blepharospasm and cervical dystonia on health-related quality of life and depression. J Neurol 249: 842-846.

30. Pekmezovic T, Svetel M, Ivanovic N, Dragasevic N, Petrovic I, et al. (2009) Quality of life in patients with focal dystonia. Clin Neurol Neurosurg 111: 161164

31. Zetterberg L, Aquilonius SM, Lindmark B (2009) Impact of dystonia on quality of life and health in a Swedish population. Acta Neurol Scand 119: 376-382.

32. Jahanshahi M, Sartory G, Marsden CD (1991) EMG biofeedback treatment of torticollis: a controlled outcome study. Biofeedback Self Regul 16: 413-448.

33. Brudny J, Korein J, Grynbaum BB, Friedmann LW, Weinstein S, et al. (1976) EMG feedback therapy: review of treatment of 114 patients. Arch Phys Med Rehabil 57: 55-61.

34. Basmajian JV (1963) Control and training of individual motor units. Science 141: $440-441$.

35. Basmajian JV (1981) Biofeedback in rehabilitation: a review of principles and practices. Arch Phys Med Rehabil 62: 469-475.

36. Coelho M, Ferreira Valadas A, Mestre T (2011) Pain and Quality of Life in the Treatment of Cervical Dystonia. European Neurological Review 41: 22-31.

37. Korein J, Brudny J, Grynbaum B, Sachs-Frankel G, Weisinger M, et al. (1976) Sensory feedback therapy of spasmodic torticollis and dystonia: results in treatment of 55 patients. Adv Neurol 14: 375-402.

38. Keefe FJ, Surwit RS (1978) Electromyographic biofeedback: behaviora treatment of neuromuscular disorders. J Behav Med 1: 13-24. 
Citation: Jahanbazi A, Chitsaz A, Asgari K (2013) Effects of EMG Biofeedback on Pain and Quality of Life in Cervical Dystonia. J Neurol Disord 2: 144. doi:10.4172/2329-6895.1000144

39. Korein J, Brudny J (1976) Integrated EMG feedback in the management of spasmodic torticollis and focal dystonia: a prospective study of 80 patients. Res Publ Assoc Res Nerv Ment Dis 55: 385-426.

40. Smania N, Corato E, Tinazzi M, Montagnana B, Fiaschi A, et al. (2003) The effect of two different rehabilitation treatments in cervical dystonia: preliminary results in four patients. Funct Neurol 18: 219-225.

41. Hurrell M (1980) Electromyographic feedback in rehabilitation. Physiotherapy 66: $293-298$

42. Brudny J, Grynbaum BB, Korein J (1974) Spasmodic torticollis: treatment by feedback display of the EMG. Arch Phys Med Rehabil 55: 403-408.

43. Leplow B (1990) Heterogeneity of biofeedback training effects in spasmodic torticollis: a single-case approach. Behav Res Ther 28: 359-365
44. Mueller J, Wissel J (2006) Visual biofeedback treatment improves cervical dystonia. Lancet Neurol 5: 864-872

45. Munts AG, Mugge W, Meurs TS, Schouten AC, Marinus J, et al. (2011) Fixed dystonia in complex regional pain syndrome: a descriptive and computational modeling approach. BMC Neurol 11: 53.

46. Molho ES, Agarwal N, Regan K, Higgins DS, Factor SA (2009) Effect of cervica dystonia on employment: A retrospective analysis of the ability of treatment to restore premorbid employment status. Mov Disord 24: 1384-1387.

47. Visser B, Koelman J, Engelbert R, Tijssen M (2013) Cervical dystonia: effectiveness of a standardized physical therapy program; study design and protocol of a single blind randomized controlled trial. BMC Neurol 13: 85. 